\title{
A Study into Snakes and Earrings and Punk Culture from the Perspective of Costume Psychology
}

\author{
Hong-ying DENG ${ }^{1}$ and Yu-mei CUI ${ }^{2, ~ *}$ \\ ${ }^{1}$ West Yan'an Road No.1882, Donghua University, Fashion \& Art Design Institute, \\ Shanghai, China, 200051 \\ ${ }^{2}$ West Yan'an Road No. 1882, Donghua University, Fashion \& Art Design Institute, \\ Shanghai, China, 200051 \\ ${ }^{*}$ Corresponding author
}

Keywords: Costume psychology, Tongue splitting, Punk, Post-modernism culture, Body modification.

\begin{abstract}
There is an old saying in the western world, "You are what you wear", and American clinical psychologist Dr. Jennifer Baumgartner once finished a pioneering treatise based on the costume psychology. Under earth-shaking changes of the age, the lifestyles of human beings have also undergone drastic changes; therefore, clothing has not just meets the function of warming and sheltering, which remains more symbolic meanings at the level of sociology. Certain dressing and clothing styles can represent the social class and lifestyles of certain social groups. Japanese movie Shakes and Earrings adapted from "Cleft Tongue" of Hitomi Kanehara, which won the Akutagawa Prize (one of the most prestigious literary awards in Japan). It tells a story that three young Japanese marginal youth figures try to realize self-salvation by body modification, but lost in a disorder of relationship and sensory stimuli. This thesis, from the perspective of the costume psychology, tends to study the inner actives and daily lifestyles of Punks under the young subculture, and also its deep connotation in the light of sociology science.
\end{abstract}

\section{An Overview of the Costume Psychology}

\section{The Definition of the Costume Psychology}

The science of the costume psychology carries out a research on the laws of psychological activities and development between the humans 'clothing behaviors, which has been referred as the external form or expressive form. Individual clothing behaviors perform the psychological features and mental states on the temporary states of human beings. The costume psychology is a subordinate branch of psychology science, which mainly studies the laws of inner actives when to choose certain dress codes from a scientific standpoint. Early in the 1920s-30s, western countries firstly tackled with fashion and clothing from the angle of psychology, so early academic researches mainly finished by psychologists. Back to 1928, BBC chose this topic and invited J. S. Flugel to do a keynote speech, which afterwards J. S. Flugel compiled The Psychology of Clothes. It officially marked the birth of costume psychology. Because this branch of subject involves other fields, such as, aesthetics, anthroponomy, philosophy, and ethics theory, confined to an interd isciplinary subject, it undergoes a long period of development. Yet, on the other hand, the property of interdisciplinary subject decides an expansion of knowledge scopes, which more closely combines with humanities and social sciences. 


\section{The Practical Significance of the Costume Psychology}

Abraham Harold Maslow, the very famous American psychologist, has created the best-known theory about hierarchy of needs, whose theory of psychological health predicated on fulfilling innate human needs in priority: physiological, safety, love/belonging, esteem, and self-actualization. Clothing has always been treated as carrier of internal sensibilities; this layer of "outer skin" could even play the function of adjustment. Moreover, it helps people seek the social orientation of them and find their own social strata or interest groups. Just as mentioned above, Punks can satisfy their safety needs by extreme body modification, split tongue, tongue or eyebrows piercings, tattoos, etc. These body modification methods leave their own spiritual totem. The inner mental activities have three classifications: meeting inner reflections and emotional experiences; satisfying a basic function of embellishment; displaying the preeminence awareness. Though subculture groups can only be regarded as secondary social communities, the spread of its moral values has also subtly influenced different mainstream culture. Most typical example as the Beat Generation of U.S.A, some few young poets and writers gathered but plays an important role on the post-modernism culture, which again considered as an unnecessary branch of post-modernism literature. To do a research on the dress codes and inner actives of customers on the aspect of the costume psychology, it can dig profoundly social and cultural meanings backwards. For clothes being a part of daily necessities, relevant right merchandising strategies can then target on customers after a meticulous knowledge of consumer behaviors. In addition, the costume psychology studies on the relationship between humans and environment, through the comprehension of socialization state, on the expansion meaning of embellishment, people could also rely on the "outer skin" to express the Ego. In a word, a research on the costume psychology can be conducive to deep discussions on the socialization behaviors of human beings.

\section{An analysis on the Role Cha racters and Inner Actives of Snakes and Earrings}

\section{The Story Outline of Snakes and Earrings}

Japanese movie Snakes and Earrings was adapted from Hitomi Kanehara's original novel, which has won the most prestigious literary awards-Akutagawa Prize and makes her the youngest people ever to receive the honor, and directed by famous Japanese theatrical director--Yukio Ninagawa. This movie tells a story of heavy grief, which isolated souls seek the ultimate meaning of living. Ruyi, a nineteen-years-old Shibuya girl, who has no work and drops out of school, in a night club met a Punk youngster called Ama. And Ama pretended to be a typical Punk, hairdressing in Mohican style and fixing piercings and plugs through his face, but to Ruyi's most intere st: his split tongue-like a snake division into two from the top of tongue. Later on, Ruyi and Ama lived together; even Ama brought Ruyi to operate a tongue splitting. The owner of tattoo shop, ASHIBA, in elaborate full-body tattoos, eyebrows piercings, and rivets on face. Ruyi began to love body modification, on the way of seeking life meaning, but she still could not find a destination with endless desperation and confusion. Finally, an incident of violence ended the current living states of the three figures, Ama killed by ASHIBA, maybe from this moment on; Ruyi really felt her real emotions and senses of existence. 


\section{The Complex Psychological Activities of Role Characters in Snakes and Earrings}

Tongue splitting (or tongue bifurcation), a type of body modification, has become popular in the western countries and nowadays it is treated as a common body alteration for the enthusiasts. According to the descriptions in the Hitomi Kanehara's novel, dental floss or fishing line will be tied through an existing tongue piercing to the tip of the tongue and then using a scalpel cut it, the whole process finally ends. Ama realized the self-salvation from the physical pains, though this extreme method deviates away from traditionally social moral values. Subculture originates from consumerism of the whole society; what's more, common material life loses its spiritual sustenance forward complete emptiness and nothingness. The movie characters seem to escape from the constraint and limitation from traditional family, society, yet, it seems like a kind of "pseudo-emancipation". For them, body can also be an object of consumption, nothing in the world obtains its senses, so they become obsessed with uncommon profligate relations. The combination of narcissism and consumerism influence right moral ethnics, even the development of social network greatly pushes its radiant scope. The movie ends with the still lonely Ruyi wandering at the Shibuya Street, all the rest of life then just compromising of emptiness and desperation? In the purely sensuous world, people ceaselessly claim desire and drift around from isolation. This can be the life recordings of real picture for a niche group, but it practically, whether you comprehend or not, exists.

\section{A Study into the Costume Psychology under the Punk Culture}

\section{The Application of Punk Culture in the Fashion Design}

Punk culture, early staged only as a branch of subculture, for example, Punk music as a type of music attitude or lifestyle, highly admired by young Punks, for its core culture, interpreted as destruction and denial to established facts and realities. Punk clothing, for its niche dressing style, gradually combines with other subculture styles, which expands its influences. From rebellion spirit, low-price, unrefined to acceptance by high-class brands, even haute couture willingly take in certain Punk elements into their design series. In general, Punk clothes obtain typical features as followed: asymmetry, minimalism, mix and match, patch jeans, leather, rivet, pins, and even extreme body modification. Punk, for its unique charisma of rebellion, favored by some independent fashion designers, explore its creative profoundness to express individuality, then more cater to the tastes of young customers.

\section{The Sociological Meaning of Punk culture}

Punk culture has been existed as a special cultural form, which presents the social identity of special groups. Because of the individual dressing style, punks realize the rights of their own body. Different from traditional social and cultural belongs of the human body; the sub-groups obtain their special cultural awareness. From subculture to the full emptiness of post-modernism, it builds the base of highly-developed economic society. Under the flourishing information society, the excess of consumerism boosts materialization, most time, people have already owned realistic objects but still not totally contented. On the way of materialization post modernizers continue lost in the spiritual world without ever appetite satisfied. On the other hand, Chinese fashion industry has experienced an earth-shaking changes after releasing of the open and reform policy, but still develops on the western process. Punks, though belonging to niche groups, it still influences the progress of the whole fashion industry. From 
1920s's haute couture, the highest end of fashion influenced the downstream (as the effect of trickle down), to street style's trickling up to the super brands, without exaggeration, Punk clothing has remained its footprints on the 20s century. Vivienne Westwood, mother of Punk, acknowledged her fashion statement after the opening "Sex" on the No. 430 of London's Kings Road, just for its contempt and rebellion against orthodox aesthetics, Punk has still taken a place in the competitive fast industry. Derive to a new outlook, but still charisma and enduring. Punk, as a rare phenomenon of fashion, even more frequently applied in the massive market, which proves its wide market prospect. Just as those individual rivets on fashion and accessories everywhere, it seems to make a strong Punk statement into the eyes of the public.

\section{Conclusion}

Shakes and Earrings superficially seems a tangled story of torture, yet, which embodies profound sociological meanings. To a great extent, for its specific glamour famous Japanese theatrical directors--Yukio Ninagawa has played its director. Perhaps a controversial topic bears more research value, just as, Punk culture, which different people hold completely opposite views. And since the Chinese translation version of Shakes and Earrings has firstly been introduced to the mainland of China, it made a sensation in the literary world. From the perspective of the costume psychology, these theses chooses these two controversial issues and make a comparison, with a purpose of exploring inner actives and lifestyles among young groups under a background of subculture. Common people can meet their highest need (as Maslow's self-actualization need) by hard work or study, but the niche communities still find no direction under desperation confined to the value orientations of anti-culture, the core of post-modernist culture. Similarly, modern people tend to be lost in a fast-pace economic pattern, may ask, how many have always tried to search their own living existence. How people wear directly express them, even dressing in an identical garment differentiates varied characteristics and tastes. And now which side of you should express in a different mood?

\section{References}

[1] Xue wen, The Cleft Tongue - The Writing Practice of "The Novel Modified by the Body", Journal of Hainan Normal University, 2009(6): 125-129.

[2] Jin xianyu, To see Japanese modern youth's lifestyles from Cleft Tongue, Literature Observer, 2012(12).

[3] Hitomi Kanehara, Cleft Tongue, Shanghai Translation Publishing House, 2009.

[4] Chang linlin, Punk clothing and its development trend, Guangxi Textile Science \&Technology, 2008(2).

[5] Li weiping, Rebellion and lost-Cleft Tongue from a post-modernist vision, Modern Literary Magazine, 2006(2).

[6] Miao li \& Wang wenge, The costume psychology, Hefei University of Technology Press, 2010(8).

[7] Liu guolian, Apparel Psychology, Donghua University Press, 1997(11).

[8] Information on http://www.xinli110.com/hangye/fzxl/201202/279836.html 